\title{
Waste Tyre Co-Pyrolysis and Engine Performance of Tyre Pyrolysis Oil: A Review
}

\author{
Faralu Muhammad Sani*1 ${ }^{1}$ and Joseph Samuel Enaburekhan ${ }^{2}$ \\ Research Scholar ${ }^{1}$ and Professor $^{2}$ \\ ${ }^{1-2}$ Department of Mechanical Engineering \\ ${ }^{1}$ Usmanu Danfodio University Sokoto, Sokoto-Nigeria \\ ${ }^{2}$ Bayero University Kano \\ Kano, Nigeria
}

\begin{abstract}
A comprehensive review that covers major works within a period of twenty-nine years (1990-2019) on waste tyre pyrolysis/copyrolysis and engine performance and emission characteristics of TPO was carried out in this study. A key issue with researchers remains on how to improve the oil yield and its quality. Waste tyre pyrolysis is established to be the most efficient and sustainable means of waste tyre disposal. It also serves as a source for alternative and renewable fuels and other by-products that can have valuable input in the industry. Co-pyrolysis is not associated with the huge burden of cost and as such is receiving particular attention. Significant research of interest that can bridge major gaps is in the co-pyrolysis of the waste tyre in combination with other wastes. There is still also the need to improve the works on engine performance and emission characteristics of TPO.
\end{abstract}

Key Words: Pyrolysis, Wastes, Tyre, Oil, Performance.

\section{INTRODUCTION}

The issue of waste tyre disposal is becoming a huge burden and great environmental concern globally. Vehicles are exponentially increasing on roads with each year and so are the wastes and pollution. Billions of waste tyres being produced are left as solid waste, used for land fillings or burnt. Land applied disposal of waste tyres has far-reaching environmental, economic, and human health consequences. Open tyre fires are polluting air by emitting carbon monoxide, sulfur dioxide, nitrogen oxides, organic pollutants, and poly-aromatic hydrocarbons (PAH). These gases can have chronic health affects like skin rashes, irritation of eyes, and respiratory problems. There has been a growing concern for development of sustainable waste tyre disposable methods. Tyre being a polymer can be subjected to thermal degradation in a process called pyrolysis to derive feedstock materials. It was found by many researchers that the products from pyrolysis can be used in different applications. There are three main products of pyrolysis of tyres, namely: gaseous products, liquid products, and the solid product called [1,2]. A co-pyrolysis of waste tyre employs the use of other additional wastes as feedstock in the pyrolysis process.

Reference [3] reported waste tyres to be excellent candidates for energy recovery, as well as solid, liquid, and gaseous by-products via pyrolysis. Approximately 1.5 billion tyres are produced globally each year with 300 million in the USA, which will all eventually become waste tyres. The accumulation of waste tyres is aggregating with each year. Not only the size of waste tyre has to be reduced, but also some useful energy has to be recovered out of it as the world clearly requires energy from alternative resources. Pyrolysis is one such method to extract energy potential products from waste tyres. It is extensively used to generate carbon black (solid product), tyre-oil (liquid product) and syngas (gas product) from waste tyres. Fuel production from tyre waste could form part of a solution to the global issues of waste tyre disposal and alternative energy resource $[4,5]$.

Reference [5] further reported that tyre pyrolysis oil (TPO) is the liquid product derived from waste tyre pyrolysis. It has been shown to have potential as an alternative to diesel with the added benefit of waste recycling and disposal. TPO can be used as a fuel directly or as a blended mixture with gasoline or diesel in boilers and internal combustion (IC) engines. Many researchers are currently indicating interest in the performance and emission characteristics of TPO. Presently, a lot of research work is being done in enhancing TPO properties by using different catalysts or employing co-pyrolysis technique with various feedstocks [6, 2]. The aim of this study is to extensively review waste tyre pyrolysis and engine performance and emission characteristics of TPO within the last thirty years. Most of existing reviews of the topic do not cover this wide period and latest trends. 


\section{ENERGY RECOVERY OF LIQUID FUEL FROM WASTE TYRE}

\subsection{Pyrolysis of Waste Tyre}

Energy in form of liquid fuel is recovered from waste tyres through a thermal degradation process called pyrolysis. Researchers have so far globally focused their attention on this interesting field. Of recent, several key works have been conducted on waste tyre pyrolysis over the past twenty five years. A critical issue that is common with researchers is identifying those factors that affect yield and product composition. References $[3,4,7]$ reported that temperature is the predominant factor influencing the distribution of gas, liquid, and solid phase pyrolysis products, and their properties. Other identified factors that influence tyre pyrolysis include heating rate, particle size, feedstock composition, pyrolysis time/tyre residence time, carrier gas flow rate/volatiles residence time, presence of steam in the carrier gas, and presence of a catalyst. Studies have suggested that waste tyres are excellent candidates for pyrolysis to recover energy and by-products. TPO have been burned successfully in test furnaces and diesel engines with typical heating value around $40 \mathrm{MJ} / \mathrm{kg}$. The oil can also yield useful chemicals for the petrochemical industry, including light olefins and aromatics. The solid char is used to create carbon black for pollutant removal. The gaseous product which includes hydrogen and various hydrocarbons can be used as fuel. Alsaleh \& Sattler [3] recommended a future study to directly compare oil yields of various reactor types (batch/fixed bed, rotary kiln, and fluidized bed), for the same tyre feedstock. Furthermore, the impact of heating rate on oil yield is to be studied in greater detail. Another research gap identified was the investigation of additional catalysts for improving oil yield. Nkosi \& Muzenda [7] suggested the integration of a treatment unit into the pyrolysis process for primary products to be of valuable quality and that the success of waste tyre pyrolysis depends on product market availability. Parthasarathy et al. [4] observed that tyres upon thermal decomposition are prone to release pollutants such as $\mathrm{SO}_{2}, \mathrm{H}_{2} \mathrm{~S}, \mathrm{HCl}, \mathrm{HCN}$, dioxins $\left(\mathrm{C}_{4} \mathrm{H}_{4} \mathrm{O}_{2}\right)$ and polycyclic aromatic hydrocarbons (PAH). Hence, there is a need of future research to focus on solving this critical issue.

Experimentally Chouaya et al. [8] investigated the pyrolysis of scrap tyres under different operating conditions such as feedstock size and pyrolysis temperature by determining the properties of the whole liquid products generated during each thermal degradation process. The work established the complete conversion temperature for the pyrolysis to be within the range 500 $550^{\circ} \mathrm{C}$. The work determined characteristics of liquid fraction by elemental analysis, chromatographic and spectroscopic techniques and distillation data. All the obtained atomic ratios were around 1 - 4 which signified that such pyrolysis liquids are a mixture of aliphatic and aromatic compounds derived from polymeric materials. The study analysed pyrolysis oil by chromatographic analysis to show that it was a complex mixture of organic compounds $\mathrm{C}_{5}-\mathrm{C}_{26}$, aromatics and a large proportion of light hydrocarbons that can be used as liquid fuels. Furthermore, the comparison distillation data in the experiments indicated that more than $40 \%$ of such pyrolysis oil fraction had the boiling point range between $180-360^{\circ} \mathrm{C}$ which is specified for diesel. The research also noted that oil viscosity decreased from 4.87 to 1.79 with increase in temperature. Banihani \& Hani [9] also experimentally investigated the effects of catalysts and their ratio on TPO and reported that waste tyre was first freed from metal cords and textiles, cleaned and cut into sizes of $5 \mathrm{~mm}$. Activated alumina and zeolite Jo catalysts were selected for the pyrolysis process that was carried out in a fixed-bed reactor at a temperature of $550^{\circ} \mathrm{C}$ and at a heating rate of $15^{\circ} \mathrm{C} / \mathrm{min}$. The catalysts were mixed with feedstock in different percentages $(10 \%, 15 \%, 25 \%$ and $35 \% \mathrm{w} / \mathrm{w})$. The study reported that results were compared with those performed without catalyst under the same conditions. The maximum liquid yield obtained from pyrolysis of waste tyre via catalysts were found to be $49.32 \%$ and $51.54 \%$ on using activated alumina and zeolite Jo catalysts respectively. However, the yield was $42.48 \%$ in the absence of a catalyst and the work suggested that fuel properties showed that it can be used as liquid fuel. In the quest for renewable and alternative fuel reference [10] worked on optimization of tyre pyrolysis conditions with the objective of getting an alternative fuel that is comparable with the traditional diesel that is available in the market. The research reported that the production of good characteristic TPO (HHV, viscosity, density, flash point, tar content, Sulphur content, etc) from scrap tyre requires working under mild conditions of input energy, temperature and inert gas carrier. Firstly, it is sufficient to purge an inert gas carrier for 30 minutes before the pyrolysis process in order to get rid of the oxidative gases (i.e. $\mathrm{O}_{2}$ and $\mathrm{H}_{2} \mathrm{O}$ ) out of the reactor thereby avoiding any oxidation process during the pyrolysis. Secondly, mild input heating energy (650W electrical input); which reflects in very low heating rate; helps to crack chemical bonds slightly giving free radicals, especially Sulphur and Hydrogen, sufficient time to react together to form $\mathrm{H}_{2} \mathrm{~S}$ instead of transferring sulphur into liquid product. In addition, other free radicals will react as well with each other producing light and not heavy molecules thereby enhancing the formation of good alternative fuel or feedstock to the industry. Thirdly, $475^{\circ} \mathrm{C}$ is enough to finish the pyrolysis process with good yield of pyrolysis products quantitatively and qualitatively. This importantly saves time and energy in the decomposition process as other works found in the literature reach temperatures up to $800^{\circ} \mathrm{C}$. This work finally suggested that TPO is comparable with the diesel as it has GCV $45 \mathrm{KJ} / \mathrm{kg}$, low density of 0.85 and $7 \%$ tar content. The oil can therefore be used as an alternative fuel in the IC engine, blending it with fossil diesel up to $25 \%$ (TPO) without any modification in the engine or any post pyrolysis 
treatment as distillation or use of additives. The identified the optimum values for tyre pyrolysis in the study were $465^{\circ} \mathrm{C}, 650$ Watts and without inert gas flow rate.

With regards to sustainable methods of waste tyre disposal and energy recovery Kommineni et al. [2] gave an insight on tyre pyrolysis processes and a detailed overview on latest research that is being done on the products of pyrolysis. The study identified the use of these products to make the pyrolysis process economically viable. The work also established that gaseous products from tyre pyrolysis mainly consist of hydrogen, lighter hydrocarbons (HC), and carbon monoxide and have the potential to generate energy. The liquid products when distilled produce gasoline like fuel and diesel like fuel. The solid product, which is mainly char, that is porous can act as a gasification catalyst and when upgraded can be used to generate carbon black (CB) which is reutilized in manufacturing of tyres. Based on market requirements and supply chain models of all tyre pyrolysis products the study suggested that strategic decisions must be taken into consideration for the process to be sustainable and a successful method to dispose waste tyres. The work thus suggested the use of hybrid technologies at industrial scale for the pyrolysis process in order to achieve a sustainable process of disposing waste tyres. In the area of future research the work concluded that more research has to be done to create an economical pathway for industrial scale tyre pyrolysis. Reference [11] presented the pyrolysis process of used tyres as a method of producing an alternative energy resource. The study reported the characteristics of used tyre materials and methods of recycling, types and principles of pyrolysis, the pyrolysis products and their compositions, effects of process parameters, and kinetic models as applied to pyrolysis process. The work reported that although some form of disagreement exists amongst various researchers it is permissible to generalize the following findings. The proximate analysis of tyre rubber shows that it is composed of about 28.6 wt. \% fixed carbon, $62 \mathrm{wt}$. \% volatilematerial, $8.5 \mathrm{wt} . \%$ ash, and 0.9 wt. $\%$ moisture. Elemental analysis reveals that tyre rubber has an estimated value of $82 \mathrm{wt} . \%$ of C, $8 \mathrm{wt} . \%$ of H, $0.4 \mathrm{wt} . \%$ of N, $1.3 \mathrm{wt} . \%$ of S, $2.4 \mathrm{wt} . \%$ of O, and 5.9 wt.\% of ash. Thermogravimetry analysis confirms that the pyrolysis of used tyre at atmospheric pressure commences at $250^{\circ} \mathrm{C}$ and completes at $550^{\circ} \mathrm{C}$. The three primary products obtained from used tyre pyrolysis are solid residue (around $36 \mathrm{wt} . \%$ ), liquid fraction or bio-crude (around 55wt.\%), and gas fraction (around 9wt.\%) each with average higher heating value (HHV) of $28 \mathrm{MJ} \mathrm{kg}^{-1}, 42 \mathrm{MJkg}^{-1}$, and $36 \mathrm{MJN}^{-1} \mathrm{~m}^{-3}$, respectively. The study concluded that although there is variation in the value of kinetic parameters obtained by different authors from the kinetic modeling of used tyres, the process is generally accepted as a first order reaction based on Arrhenius theory.

Table 1: Proximate, Ultimate Analysis and Higher Heating Value of Tyre Waste (Adopted from Aslan et al. [1])

\begin{tabular}{|l|c|}
\hline \multicolumn{1}{|c|}{ Proximate Analysis (dry basis) (wt. \%) } & \\
\hline Volatil Matter & 69.9 \\
\hline Fixed Carbon (calculated by difference) & 24.9 \\
\hline Ash & 5.3 \\
\hline Ultimate Analysis (dry and free basis) & \\
\hline C & 84.4 \\
\hline H & 7.1 \\
\hline N & 0.4 \\
\hline S & 2.1 \\
\hline O (calculated by difference) & 6.2 \\
\hline Higher Heating Value $\left(\mathrm{MJkg}^{-1}\right)$ & 32.54 \\
\hline
\end{tabular}

A particular attention of research is also being devoted to waste tyre treatment technologies as means of sustainable waste tyre disposal systems and source for alternative fuels. Pilusa et al. [12] evaluated the viability of pyrolysis technology as a treatment process for waste tyres with the aim of producing alternative fuel and other high value products. A financial model was formulated to evaluate the economic feasibility of this technology as an alternative disposal method as well. The study discovered that pyrolysis technology becomes more viable when there are guaranteed product off-takes at a given price. The work noted that further processing of the crude tyre oil and carbon black is important for production of consistent quality products. In the same direction, references $[13,14]$ reviewed remedial waste tyre technologies and utilization for energy and material recovery. The studies identified three processes: pyrolysis, gasification and liquefaction (PGL) as the potential solutions to address the waste tyre problem. Furthermore, PGL processes have huge potential for business. However, the success of any operation depends on several economic and environmental factors such as capital and operating costs, feed availability, permitting process and emission from these operations. Nonetheless it was recommended that efforts should be made to research and develop more efficient waste tyre treatment systems. 


\subsection{Co-pyrolysis Process with Tyre Wastes}

The tyre co-pyrolysis technique is a process where other wastes with appreciable energy content are added as feedstock in proportion with waste tyre during a thermal degradation process. Presently, this trend has become popular with researchers in an effort to improve oil yield and properties. Reference [6] converted tyre waste and rice husk into biofuel and other chemicals by using externally heated fixed-bed co-pyrolysis reactor. The tyre waste and rice husk were investigated for suitability as feedstock by proximate and ultimate analysis, gross calorific values and thermo-gravimetric analysis. Collected solid tyre waste was chipped and then mixed with rice husk at different proportions. Feed sizes of $2 \mathrm{~cm} \times 1 \mathrm{~cm} \times 1 \mathrm{~cm}$ for tyre waste and $1800-2300 \mu \mathrm{m}$ for rice husk were used at 60 minutes running time. The process conditions were varied by the percentage proportions of tyre and rice husk at a reactor temperature of $450{ }^{\circ} \mathrm{C}$. The study reported that the liquid and char products were collected separately while the gas was flared into the atmosphere. The proportion of wastes was found to influence the product yields and feedstock to oil energy conversion efficiency (FOECE) significantly. The maximum liquid yield was $52 \mathrm{wt} \%$ for $50 \%$ tyre and $50 \%$ rice husk blend at a reactor temperature of $450{ }^{\circ} \mathrm{C}$ for zero $\mathrm{N}_{2}$ gas flow. Liquid products obtained at these conditions were characterized by physical properties, chemical analysis and fractional distillation. The work indicated that it is possible to obtain liquid products that are comparable to petroleum fuels and valuable chemical feedstock from the selected wastes if the pyrolysis conditions are accordingly chosen.

Table 2: Characteristics of Pyrolytic Liquids in Comparison to Petroleum Products (adopted from Hossain et al. [6])

\begin{tabular}{|l|l|l|l|l|}
\hline Analysis & $\begin{array}{l}\text { Tyre Waste } \\
\text { Pyrolysis Liquid }\end{array}$ & $\begin{array}{l}\text { Rice Husk Pyrolysis } \\
\text { Liquid }\end{array}$ & Co-pyrolysis Liquid & Diesel \\
\hline Density $\left[\mathrm{kg} / \mathrm{m}^{3}\right]$ & 970 & 1050 & 832 & 827 \\
\hline Viscosity $[\mathrm{cSt}]$ & 5 & 3.609 & 5 & 2.61 \\
\hline Flash Point $[\mathrm{C}]$ & 30 & 58 & 75 & $60-80$ \\
\hline Pour Point $[\mathrm{C}]$ & -4 & ND & -6.2 & -33 to -1 \\
\hline HHV $[\mathrm{MJ} / \mathrm{kg}]$ & 42.28 & 16.298 & 33.6 & 45.18 \\
\hline
\end{tabular}

Many other works involving co-pyrolysis processes are being conducted to primarily increase oil yield and product properties. Chen et al. [15] found that co-pyrolysis could increase the total peak area of volatile matters (10.92-15.34\%) and proportion of hydrocarbons, especially for olefins (13.25-37.42\%). The process as reported can inhibit non-hydrocarbon compounds (about $63 \%$ ) of volatile products. The study suggested that the co-pyrolysis of kitchen waste with tyre waste could serve as a potential means of improving the quality of pyrolysis oil. Martínez et al. [16] worked on co-pyrolysis of biomass with waste tyres where pine woodchips $(15 \mathrm{~mm})$ and waste-tyre scraps $(5 \mathrm{~mm})$ nominal sizes were fed as feedstock into a fixed bed reactor and a continuous auger reactor. The results showed positive effects of co-pyrolysis resulting from a composition of waste tyre and biomass. This was more notable and synergetic in the auger reactor. The research found that whilst acidity, density and oxygen content decreased; the $\mathrm{pH}$ and calorific value increased leading to upgraded pyrolysis oil. Moreover, it was also observed that an increase of waste tyre ratio in the feedstock significantly decreased the amount of aldehydes and phenolic compounds, which is beneficial for improving the stability of the pyrolysis oil. Ucar and Karagoz [17] reported on co-pyrolysis of pine nut shells with scrap tyres where pine nuts were milled and sieved to give an average particle size of $2 \mathrm{~mm}$ and scrap tyres were grinded in a cryogenic medium and sieved to give an average particle size of $1.5 \mathrm{~mm}$. The co-pyrolysis of pine nut shells (PNS) with scrap tires (ST) at different blend ratios was carried out at $500^{\circ} \mathrm{C}$. An increase in composition of ST into PNS increased bio-oil yields and also improved bio-oil characteristics when compared with the pyrolysis of PNS. The work found an increase of heating values of bio-oil with the addition of ST in the co-pyrolysis mixture with the exception of PNS/ST (4:1) composition. Furthermore, study also observed that the heating values of gas products and levels of hydrogen and hydrocarbons (from $\mathrm{C} 1$ to $\mathrm{C} 4$ ) in the gas products from the co-pyrolysis of PNS/ST blends were higher than that of the pyrolysis of PNS. The heating values of chars produced from the co-pyrolysis blends were found to be in the range of 31.1 and $32.9 \mathrm{MJkg}^{-1}$.

The issue of using catalysts in a co-pyrolysis process is not left untouched by researchers. Wang et al. [18] investigated and analyzed the effect of $\mathrm{CaO}$ to HZSM-5 mass ratio on pyrolytic products distribution for an upgraded liquid oil production via fast co-pyrolysis of bamboo residual and waste tyre. The study revealed that the catalytic fast co-pyrolysis of bamboo residual and waste tyre increased the relative contents of aromatics and olefins. Moreover, dual catalytic stage of CaO and HZSM-5 further facilitated the increase of relative contents of aromatics and olefins significantly, and inhibited the formation of undesirables like acids. The study suggested that a maximum yield of hydrocarbons could be reached at HZSM-5 to CaO mass ratio of 3:2. Furthermore, the co-modified HZSM-5 promoted the relative contents of aromatics and olefins compared with the fresh ones, which showed great promise for upgrading the quality of the liquid oil. Reference [19] reported on the effect of untreated fly-ash 
(class F) as catalyst for the co-pyrolysis of scrap tyre and polypropylene (plastic) at $300^{\circ} \mathrm{C}$ and atmospheric pressure. A batch type pyrolysis reactor was used to establish maximum oil yield of $(23.33 \%)$ with co-pyrolysis of $60 \%$ tyre and $40 \%$ plastic in the presence of $20 \mathrm{wt} \%$ fly ash catalyst due to the synergistic interaction of tyre and plastic waste. The work also investigated the effect of fly-ash on the co-pyrolysis using Pyro-GC/MS at $500^{\circ} \mathrm{C}$. The pyro-GC/MS studies showed that the addition of raw flyash enhanced the product quality by significantly reducing the nitrogen and sulfur containing compounds. However, there was also a significant improvement in the composition of alkane with fly-ash addition due to presence of high quantity of silicon oxide. Nonetheless, Babajo et al. [20] reviewed on co-pyrolysis of biomass with waste tyre and observed that the use of catalysts and other chemicals to improve the quality of pyrolysis oil is many times associated with a burden of huge costs. The study indicated that the co-pyrolysis technique offers simplicity and effectiveness in order to produce high-grade pyrolysis oil. This is achieved by improving the characteristics of the pyrolysis oil; examples here include: reduction in oxygen and water contents, and increase in oil yield and calorific value of the pyrolysis oil as indicated by many studies.

Researchers have carried out co-pyrolysis by using multiple wastes with tyre waste as feedstock. Grigiante et al. [21] conducted the pyrolysis of several wastes such as polymers (PE, PVC, and PS), sewage sludge, waste tyres, and waste wood in form of spruce sawdust. The waste tyre sample was shredded and crumbed to produce a $8-10 \mathrm{~mm}$ size, without steel in it. The sewage sludge sample was furnished by an urban waste-water treatment plant, dehydrated in the plant by belt-press filtration and dried. The processes were carried out by using a pyrolysis bench scale reactor and products were investigated by thermogravimetry coupled to mass spectrometry, TG-MS and TG-GC-MS on analytical and energetic point of view. The work reported that the pyrolysis of all the wastes took place within the range of $400-600^{\circ} \mathrm{C}$ and led to the reduction of $90 \%$ by mass for plastics, $50 \%$ for sludge, and ca. $60 \%$ for tyres, with a production of a fuel gas phase particularly rich in hydrocarbons with estimated L. H. V. from 15 to $32.8 \mathrm{MJ} / \mathrm{kg}$ for sewage sludge and plastics, respectively. The study concluded by proposing a schematic energetic analysis with a view of obtaining environmental friendly products as raw material in the industry, particularly from sewage sludge residue. In another work Abnisa [22] studied the pyrolysis of oil palm solid wastes and co-pyrolysis of palm shell with plastic and tyre waste in a PhD thesis. In the study palm oil wastes were obtained, washed and subsequently dried under the sun for one day. The dried samples were ground and screened to give particle sizes that ranged from 1.0 to $2.0 \mathrm{~mm}$ and eventually dried again in an oven at $105{ }^{\circ} \mathrm{C}$ for 24 hours to remove moisture. A 310 stainless steel reactor was used to carry out the pyrolysis process by charging $200 \mathrm{~g}$ of sample. The study indicated that co-pyrolysis technique can improve the characteristics of pyrolysis oil and its yield. Improved characteristics included: reduction in the oxygen and water contents, and an increase in the calorific value of oil. The work further reported that the co-pyrolysis technique also increased the quality of by-products. However, the oil yield from co-pyrolysis also contained the aqueous phase as it was the case with the pyrolysis of palm shell alone. The results of the study showed that a recovery of liquid fuel from the aqueous phase was successfully achieved by using catalytic conversion.

Many other interesting studies in the area of waste tyre co-pyrolysis are being continuously pursued by scholars and researchers worldwide. Bicakova and Straka [23] worked with waste tyres of grain size 1-5 mm containing less than 50\% of natural rubber with two different types of bituminous coal. Steel parts were removed from the waste tyres by magnetic separation and subjected to thermal decomposition. A slow co-pyrolysis of $1 \mathrm{~kg}$ of waste tyre/coal mixtures with 15,30 and $60 \mathrm{wt} \% \mathrm{waste}$ tyres on a laboratory scale was carried out using a quartz reactor in a stationary bed. The mixtures were heated at a rate of $5^{\circ} \mathrm{C} / \mathrm{min}$ up to the final temperature of $900^{\circ} \mathrm{C}$ with a soaking time of $30 \mathrm{~min}$ at the required temperature. The influence of the admixture in the charge on the amount and composition of obtained coke and tar was determined. It was found that there was a smokeless fuel/carbonaceous sorbent and a high yield of tar. The obtained tars contained mostly maltenes (80-85 wt \%). FTIR analysis showed that the maltenes from the co-pyrolysis of coal/waste tyres significantly exhibited lower aromaticity as compared with that from coal alone. This suggested that the gas obtained from the co-pyrolysis contained a high amount of hydrogen (above 60 vol\%) and methane (above $20 \mathrm{vol} \%$ ). Onenc et al. [24] investigated co-pyrolysis of scrap tyres with oily wastes and reported the conversion of the wastes into liquid fuels. The pyrolysis of bilge water oil and oil sludge from ships, scrap tyres and their blends was carried out at 400 and $500^{\circ} \mathrm{C}$ in the absence and presence of catalyst. A commercial fluid catalytic cracking catalyst and Red Mud were used as catalysts. The pyrolysis oils were characterized using gas chromatography-mass selective detector (GC-MSD) and $1 \mathrm{H}$ nuclear magnetic resonance (1H-NMR). The study suggested that co-pyrolysis of scrap tyre with oily wastes from ships produced oil that could be used as fuel. On the other hand, pyrolysis of tyre alone produced oil that could be used as a chemical feedstock. The results obtained in the work showed that co-pyrolysis of oily wastes with scrap tyres could be an environmentally friendly way for the transformation of hazardous wastes into valuable fuels and chemicals.

\section{Engine Performance and Emission Characteristics of TPO}

Many researchers over time have shown keen interest in the performance and emission characteristics of TPO. Currently, a lot of research work is being targeted to enhance TPO properties either by using different catalysts or employing the co-pyrolysis technique. Abburi et al. [25] investigated the performance and emission characteristics of tyre pyrolysis oil on a computerized 4stroke single cylinder water cooled DICI diesel engine. In the initial stage the tests were conducted by using fossil diesel and base 
line data was generated for the purpose of comparison. Eventually experimental investigations were carried out on the same engine with the same operating parameters by using the tyre pyrolysis oil which was blended with diesel in different proportions such as T10 (10\% TPO and 90\% fossil diesel), T20 and T30. The study reported that among the three blends T20 showed better engine performance and emission characteristics and suggested it to be the optimum blend. Pote and Patil [26] reported that tests were conducted on a diesel engine with $100 \%$ diesel and then blends of TPO in various proportions as $10 \%, 25 \%, 35 \%, 50 \%$, $60 \%, 75 \%$ and $90 \%$ at various loads. It was observed that performance indicators like BP, IP and BMEP improved with rise in the proportion of TPO for all loads. Increase in the BTE was highest for moderate load up to $2.6 \mathrm{~kg}$ and maximum for TPO 90. The study further reported that TPO 35 exhibited maximum mechanical efficiency at higher load. Lower specific fuel consumption was obtained for TPO10 blend at low load and maximum at TPO 60. On emission analysis, the work further reported that CO emission tends to reduce up to moderate load, but increases consistently with increase in load. HC emission was found to decrease with increase in TPO proportions with minimum for TPO 90 at all loading conditions. Furthermore $\mathrm{CO}_{2}$ emission gradually increased with progressive rise in load and increased rapidly for higher loads. NOx emission and smoke increased gradually with increase in the TPO proportion. The study suggested that analysis indicated TPO 90 to be the better alternative to enhanced output and efficiency. However, TPO 10 is the recommended blend to achieve lower fuel consumption and emissions. The work concluded that moderate proportion of TPO (TPO35) gave highest cylinder pressure and reduction in fragrant sulfur. In the area of mathematical modelling, Patel and Brahmbhatt [27] prepared response surface methodology (RSM) based prediction model for specific fuel consumption (SFC) as a response. The study designed the regression model to predict SFC using RSM with central composite rotatable design (CCRD). In the development of the regression models, injection timing, compression ratio, injection pressure, and engine load were considered as controlled variables. The models showed that injection pressure and compression ratio were the most influencing variables for the SFC. TPO and diesel blends were used as fuel in CI engine to attest the validity of the regression model. In the experiments, four parameters (injection timing, compression ratio, injection pressure, and engine load) with five levels for each were used for optimization. The work succeeded in establishing a good correlation between experimental and predicted SFC values under the optimal conditions.

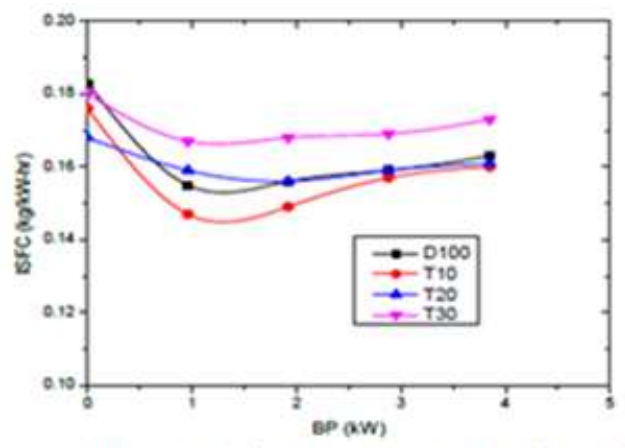

Figure 1: Brake Power versus Indicated Specific Fuel Consumption (ISFC) (Adopted from Abburi et al. [25] )

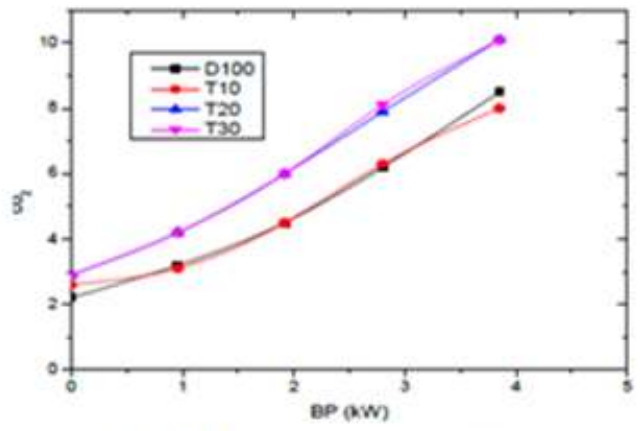

Figure 2: Brake Power versus $\mathrm{CO}_{2}$ Emission (Adopted from Abburi et al. [25] )

Verma et al. [5] studied the potential of fuels derived from waste tyres as alternatives to diesel. Production methods and the influence of reactor operating parameters (such as reactor temperature and catalyst type) on oil yield were outlined. The work reported these parameters to have a major effect on the performance and emission characteristics of diesel engines when using waste tyre derived fuels. In general, the derived fuels were reported to increase the brake specific fuel consumption and decrease the brake thermal efficiency. The review observed that majority of studies indicate that NOx emissions increase with increase in waste tyre derived fuels; however, a few studies contradict such trend. A similar increasing trend has been observed for $\mathrm{CO}$ and $\mathrm{CO}_{2}$ emissions. Regarding $\mathrm{HC}$ emission, although most studies reported its increase owing to lower cetane number and higher density; nonetheless, some studies reported reduced HC emissions. The study finally reported that it has been found that the higher aromatic content in waste tyre derived fuels can lead to increased particulate matter emissions and recommended that a significant research gap exists in the area of PM analysis for TPO blended fuels.

\section{CONCLUSION}

A comprehensive review that covers major works within a period of twenty nine years (1990-2019) on waste tyre pyrolysis/copyrolysis and engine performance and emission characteristics of TPO was carried out in this study. The work has successfully identified key issues with researchers and areas that require future attention. Waste tyre pyrolysis is established to be the most efficient and sustainable means of waste tyre disposal. Above all it serves as a source for alternative and renewable fuels and other by-products that can have valuable input in the industry. Major arguments with researchers remain on how to improve oil yield 
and its quality. The use of catalysts and co-pyrolysis techniques are the options adopted to achieve the goal. Importantly, copyrolysis is not associated with huge burden of cost and as such is being receiving particular attention. A significant research of interest that can close major gaps is in the co-pyrolysis of waste tyre in combination with other wastes. There is still a need to improve the works on engine performance and emission characteristics of TPO. Most of the works in existence are not specifically clear but somewhat ambiguous.

\section{REFERENCES}

1. D. I. Aslan, P. Parthasarathy, J. L. Goldfarb and S. Ceylan, "Pyrolysis reaction models of waste tyres: application of master-plots method for energy conversion via devolatilization," Waste Management, ScienceDirect, Elsevier, 68 (2017), pp. 405-411, 2017.

2. R. Kommineni, H. Boddapu and S. Thomas, "Scope of pyrolysis process as a sustainable method to dispose waste tyres: a review. air pollution and control, Energy, Environment, and Sustainability, Springer, pp. 247-260, https://doi.org/10.1007/978-981-10-7185-0_14, 2018.

3. A. Alsaleh and M. L. Sattler, "Waste tyre pyrolysis: influential parameters and product properties," Current Sustainable/Renewable Energy Reports, 1, pp. 129-135, DOI 10.1007/s40518-014-0019-0, Springer, 2014.

4. P. Parthasarathy, H. S. Choi, H. C. Park, J. G. Hwang, H. S. Yoo, B-K. Lee and M. Upadhyay, "Influence of process conditions on product yield of waste tyre pyrolysis- A review," Korean Journal of Chemical Engineering, 33(8), pp. 2268-2286, DOI: 10.1007/s11814-016-0126-2, 2016.

5. P. Verma, A. Zare, M. Jafari, T. A. Bodisco, T. Rainey, Z. D. Ristovski and R. J. Brown, "Diesel engine performance and emissions with fuels derived from waste tyres," Scientific Reports, 8:2457, www.nature.com/scientificreports, DOI:10.1038/s41598-018-19330-0, 2018.

6. M. S. Hossain, M. R. Islam, M. S. Rahman, M. A. Kader and H. Haniu, "Biofuels from Co-pyrolysis of solid tyre waste and rice husk," Energy Procedia, Elsevier, vol. 110, pp. 453-458, Open Access: https://doi.org/10.1016/j.egypro.2017.03.168, March 2017.

7. N. Nkosi, and E. Muzenda, "A review and discussion of waste tyre pyrolysis and derived products," Proceedings of the World Congress on Engineering 2014, vol. II, July 2 - 4, 2014, London, U.K., 2014.

8. S. Chouaya, M. A. Abbassi, R. B. Younes and A. Zoulalian, "Scrap tyres pyrolysis: product yields, properties and chemical compositions of pyrolytic oil," Russian Journal of Applied Chemistry, Vol. 91, No. 10, pp. 1603-1611, Pleiades Publishing Ltd., 2018.

9. F. F. Banihani and Z. F. Banihani, "The Effect of catalyst ratio on the pyrolysis yields for waste tyre," American Journal of Chemical Engineering, 6(4), pp. 60-64, doi: 10.11648/j.ajche.20180604.14, 2018.

10. R. Alkhatib, "Development of an alternative fuel from waste of used tyres by pyrolysis," Environmental Engineering, Ecole des Mines de Nantes, English. NNT : 2014EMNA0197, HAL tel- 01186556, 2014.

11. J. I. Osayi, S. Iyuke, and S. E. Ogbeide, Biocrude production through pyrolysis of used tyres. Journal of Catalysts, vol. 2014, pp. 1-9, Article ID 386371, Hindawi Publishing Corporation, http://dx.doi.org/10.1155/2014/386371, 2014.

12. J. Pilusa, M. Shukla and E. Muzenda, "Economic assessment of waste tyres pyrolysis technology: a case study for Gauteng Province, South Africa," International Journal of Research in Chemical, Metallurgical and Civil Engineering (IJRCMCE,) vol. 1, Issue 1, pp. 41-49, http://dx.doi.org/10.15242/ IJRCMCE.E1113542 41, 2014.

13. M. Labaki and M. Jeguirim, "Thermo-chemical conversion of waste tyres - a review," Environmental Science and Pollution Research, Springer, 24, pp. 9962-9992, DOI 10.1007/s11356-016-7780-0, 2017.

14. E. Muzenda, "A comparative review of waste tyre pyrolysis gasification and liquefaction (PGL) processes," International Conference on Chemical Engineering \& Advanced Computational Technologies (ICCEACT), pp. 40-45, November 24-25, 2014, Pretoria, South Africa, http://dx.doi.org/10.15242/IIE.E1114021, 2014.

15. J. Chen, X. Ma, Z. Yu, T. Deng, X. Chen, L. Chen and M. Dai, “A study on catalytic co-pyrolysis of kitchen waste with tire waste over ZSM-5 using TG-FTIR and Py-GC/MS," Bioresource Technology, Elsevier, vol. 289, 121585, https://doi.org/10.1016/j.biortech.2019.121585, October 2019.

16. J. D. Martínez, A.Veses, A. M. Mastral, R. Murillo, V. N. Maria, P. Neus, A. Anna, B. Jordi and G. Tomas, “Copyrolysis of biomass with waste tyres: upgrading of the liquid bio-fuel," Fuel Processing Technology, 119, pp. 263-271, 2014.

17. S. Ucar, and S. Karagoz, "Co-pyrolysis of pine nut shells with scrap tires," Fuel. ScienceDirect, Elsevier, 137, pp. 8593, 2014.

18. J. Wang, Z. Zhong, K. Ding, B. Zhang, A. Deng, M. Min, P. Chen, and R. Ruan, "Co-pyrolysis of bamboo residual with waste tyre over dual catalytic stage of $\mathrm{CaO}$ and co-modified HZMZ-5," Energy. Elsevier, vol. 133, pp. 90-98, https://doi.org/10.1016/j.energy.2017.05.146, 15 August 2017. 
19. A. Mohan, S. Dutta, V. Madav, S. S. Bhushnoor, J. F. Garcia \& P.T. Williams, "Co-pyrolysis of scrap tyre and plastic using coal derived fly-ash,” 27th European Biomass Conference and Exhibition, pp. 1501-1506, 27-30 May 2019, Lisbon, Portugal, 2019.

20. S. A. Babajo, J. S. Enaburekhan and I. A. Rufai, "Review on production of liquid fuel from co-pyrolysis of biomass with scrap/waste tyre," Journal of Applied Science and Environmental Management, vol. 23 (8), pp. 1475-1482, DOI: https://dx.doi.org/10.4314/jasem.v23i8.10, 2019.

21. M. Grigiante, M. Ischia, M. Baratieri, R. D. Maschio and M. Ragazz, "Pyrolysis analysis and solid residue stabilization of polymers, waste tyres, spruce sawdust and sewage sludge, Waste Biomass Valor,Springer, 1, pp. 381-393, doi 10.1007/s12649-010-9038-2, 2010.

22. F. Abnisa, "Study on pyrolysis of oil palm solid wastes and co-pyrolysis of palm shell with plastic and tyre waste," Thesis submitted to the Faculty of Engineering, University Of Malaya, Kuala Lumpur for the fulfilment of the requirements for the degree of Doctor of Philosophy, 2015.

23. O. Bicakova and P. Straka, "Co-pyrolysis of waste tire/coal mixtures for smokeless fuel, maltenes and hydrogen-rich gas production," Energy Conversion and Management, ScienceDirect, Elsevier, http://dx.doi.org/10.1016/j.enconman.2016.02.069, 2016.

24. S. Onenc, M. Brebu, C. Vasile and J. Yanik, "Co-pyrolysis of scrap tyres with oily wastes," Journal of Analytical and Applied Pyrolysis, ScienceDirect, Elsevier, 94 (2012), pp. 184-189, 2012.

25. R. Abburi, B. Srinivas, and K. S. Rao, "Experimental Investigations on Diesel Engine Fueled with Tyre Pyrolysis Oil and Diesel Blends," International Journal of Engineering Research \& Technology (IJERT), vol. 3, Issue 1, pp. 1213-1219, January 2014.

26. R. N. Pote, and R. K. Patil, "Combustion and emission characteristics analysis of waste tyre pyrolysis oil," Springer Nature Journal, SN Applied Sciences, 1:294, https://doi.org/10.1007/s42452-019-0308-8, 2019.

27. S. C. Patel and P. K. Brahmbhatt, "Mathematical modelling of specific fuel consumption using response surface methodology for CI engine fuelled with tyre pyrolysis oil and diesel blend," Proceedings of the $5^{\text {th }}$ International Conference on Frontiers in Intelligent Computing: Theory and Applications, Advances in Intelligent Systems and Computing 515, pp. 11-19, Springer Nature Singapore Pte Ltd, DOI 10.1007/978-981-10-3153-3_2, 2017. 